\title{
Physiotherapy and rehabilitation students' opinions on anatomy education: a cross-sectional survey study
}

\author{
DOI: https://doi.org/10.5114/pq.2020.94507
}

\author{
Begumhan Turhan \\ Department of Physical Therapy and Rehabilitation, Faculty of Health Sciences, Hasan Kalyoncu University, \\ Gaziantep, Turkey
}

\section{Abstract}

Introduction. The study aim was to establish physiotherapy students' opinions about anatomy education, to explore attitudes towards studying anatomy, and thus to evaluate possibilities to improve anatomy education.

Methods. Second-year physiotherapy students (98 females, 57 males) voluntarily participated in this study. Data were obtained by a questionnaire, which consisted of 35 questions.

Results. The participants' mean age was $22 \pm 1.77$ years. The grade point average of females was higher than that of males $(p=0.001)$. Although the study duration per week and grade point average were moderately correlated in females $(r=0.397$, $p=0.001)$, no correlation was determined in males. The statement 'Anatomy courses motivate me for my carrier' achieved the highest mean score $(1.45 \pm 0.8)$. The least mean score $(0.21 \pm 0.2)$ regarded the association between the given anatomy education and clinical practice. For $75.48 \%$ of the students, the endocrine system was the most interesting. The musculoskeletal system was learnt the best (69.03\%). Video records and course notes given by the lecturer were the most beneficial studying materials for practical and theoretical anatomy lectures, respectively $(p<0.05)$. The textbook recommended by the lecturer turned out the least beneficial material for both practical $(1.74 \pm 0.82)$ and theoretical $(1.17 \pm 0.83)$ anatomy $(p<0.05)$.

Conclusions. It is anticipated that interactive educators will be more helpful to teach the lessons. Moreover, it seems that anatomy education in physiotherapy and rehabilitation departments may need revisions to enhance students' motivation and improve academic learning.

Key words: basic science, anatomy education, physiotherapy education, anatomy curriculum

\section{Introduction}

Anatomy is defined as a visual science of studying the normal shape and structure of organs, the locations of the organs, and the structural and functional relationships between them [1]. It plays a very important part in the foundation of healthcare education. It is a fact that healthcare professionals require a good knowledge of anatomy to be better in their fields [2]. Anatomy is a discipline taught to students of medicine, dentistry, and health sciences in the first year of their education. It is also the basis for medical terminology and clinical sciences [3]. In some professions allied to medicine, such as physiotherapy, students gain a profound understanding of anatomy in practice, probably as a result of their experiences in extensive peer examination and living anatomy during the course of the programme [4].

In Turkey, the extent of a bachelor's degree in physiotherapy is 240 ECTS points, standardized for 4 years of full-time study, and the timing for anatomy inclusion in the curriculum varies between faculties (4-6 hours a week). Anatomy is taught to physiotherapy students in their first year at the university. It is one of the basic medical sciences, and the course is compulsory in the physiotherapy and rehabilitation curriculum. Physiotherapists know the range of gross anatomical knowledge required for safe and effective clinical practice [5-7]. At Hasan Kalyoncu University, physiotherapy students complete an anatomy curriculum consisting of theoretical lectures at classroom and practical lectures in laboratory during their first year. The curriculum for each semester is delivered over
14 weeks and includes 4 hours of theoretical lectures and 2 hours of practical lectures with plastic models per week. Students have anatomy I classes in the first semester and anatomy II in the second semester. Specifically, anatomy I covers the bones, articulations, and the muscular system, and anatomy II comprises the circulatory, lymphatic, respiratory, endocrine, digestive, urogenital, and nervous systems.

Anatomy knowledge is very necessary for performing the physical examination of a patient, making the correct evaluation, and sharing the findings with the patient and the other health staff $[8,9]$. Therefore, excellent anatomy education is needed for the training of a qualified physiotherapist. Studies should be carried out to improve and update the anatomy education which is taught in physiotherapy and rehabilitation departments.

Numerous researchers have investigated the educational approaches employed within anatomy curricula [10]. But, studies that examine the anatomy curriculum in physiotherapy education are rare. It is very important to evaluate feedbacks obtained from physiotherapy students through surveys and to reflect the results in the anatomy education process in the following years.

In this study, the opinions and perceptions of secondyear students of Hasan Kalyoncu University, Department of Physical Therapy and Rehabilitation, related to anatomy education were examined. The aim was to explore the students' attitude towards studying anatomy and thus to evaluate possibilities to improve anatomy education. I hope that the study will contribute to the development of education techniques,

Correspondence address: Begumhan Turhan, Hasan Kalyoncu University, Faculty of Health Sciences, Department of Physical Therapy and Rehabilitation, Havaalani 8. Km Şahinbey, Gaziantep, Turkey, e-mail: begum.aliosmanoglu@hku.edu.tr 
to the effectiveness of anatomy lectures intended for physiotherapy students, as well as to an increase in the quality of education.

\section{Subjects and methods}

\section{Participants}

Second-year students of Department of Physical Therapy and Rehabilitation, Faculty of Health Sciences, Hasan Kalyoncu University, participated in this cross-sectional descriptive-analytic and survey-based study. All the data were collected in September during the 2018/2019 academic year. The survey questionnaire was implemented among a total of 155 students (98 females, 57 males), who voluntarily participated in the study. It was $37.80 \%$ of the whole physiotherapy student population (155/410) and $95.67 \%$ of secondyear students (155/162). The students were motivated by the fact that they would have an important contribution to the development of the teaching methods of the course. The inclusion criteria were having completed the anatomy I and anatomy II lectures and having just completed the first year. These criteria were necessary because the students' attitudes towards anatomy lectures should have been fresh. The survey was administered by a staff member who did not deliver the lectures.

\section{Survey structure}

It was not a standardized instrument and was used as a guideline for this study as it was designed to collect data on physiotherapy students' views about gross anatomy education. Data were obtained by a questionnaire, prepared by the researcher (with 9 years of experience in anatomy education) in accordance with the literature. The questionnaire consisted of 35 closed-ended questions. Likert type scale was used in 26 questions (from -2 for 'completely disagree,' through 'disagree,' 'no idea,' 'agree,' up to 2 for 'completely agree'). There was a control question (one of the primary questions of the questionnaire was duplicated), which showed if the answers were reliable. The survey included questions about the demographic characteristics, grade point average (based on a 100-point scale), thoughts about anatomy education, and resources used while studying. The purpose of the study was explained to the students and hard copies of the questionnaires were distributed to them. It was optional for the participants to write their identity for the reliability of the feedback.

\section{Data analysis}

The analysis of data was performed by using the SPSS 21 (IBM Corp., Armonk, USA) statistical package. Descriptive statistics (mean, standard deviation, frequency, percentage distribution table) were established. Also, frequency and percentage distribution of each Likert type question were calculated and analysed. Categorical variables were compared with the chi-square test and expressed as counts and percentages. The Kruskal-Wallis $\mathrm{H}$ test served to compare the groups of resources applied to study the practical and theoretical part of anatomy. The results of numerical variables were presented as means \pm standard deviations and medians. The Mann-Whitney $U$ test was used to compare numerical data for the two genders. Spearman correlation coefficient was employed to determine the relationships between two numerical variables. The $p$-value of 0.05 was considered to be statistically significant.

\section{Ethical approval}

The research related to human use has complied with all the relevant national regulations and institutional policies, has followed the tenets of the Declaration of Helsinki, and has been approved by the Hasan Kalyoncu University Research Ethics Committee of the Faculty of Health Sciences (decision No. 2018/11).

\section{Informed consent}

Informed consent has been obtained from all individuals included in this study.

\section{Results}

The mean age of the study participants was $22 \pm 1.77$ years $(\min =19, \max =26)$. Descriptive data analysis results are given as the characteristics profile of the subjects in Table 1 . There was a greater percentage of female students (63\%).

Overall, $71 \%$ of the students stated that they had participated in both theoretical and practical anatomy lectures. It was determined that $15 \%$ of them had participated in theoretical lectures only and $6 \%$ had taken part in the practical part only; $8 \%$ of the students had serious attendance problems. There was no correlation between attendance to the lectures and grade point average $(p>0.05)$.

The grade point average of female students was significantly higher than that of male students $(p=0.001)$. A moderate positive correlation was observed between the grade point average of female students and study duration in a week $(r=0.397, p=0.001)$. There was no significant correlation between the grade point average of male students and study duration in a week ( $r=0.086, p=0.062)$.

The responses were scored in the Likert scale, from -2 to 2 points for 'completely disagree' and 'completely agree' comments, respectively. First and second highest scores were pertained to 'Anatomy courses motivate me for my carrier'

Table 1. The characteristics of study participants $(n=155)$

\begin{tabular}{|c|c|c|c|}
\hline Characteristics & $n$ & $\%$ & $p$ \\
\hline \multicolumn{4}{|l|}{ Gender } \\
\hline Female & 98 & 63 & \multirow{2}{*}{0.132} \\
\hline Male & 57 & 37 & \\
\hline \multicolumn{4}{|c|}{ Grade point average } \\
\hline$\leq 49$ & 38 & 24.5 & \multirow{6}{*}{0.028} \\
\hline $50-59$ & 37 & 23.8 & \\
\hline $60-69$ & 21 & 13.5 & \\
\hline $70-79$ & 33 & 21.2 & \\
\hline $80-89$ & 23 & 14.8 & \\
\hline$\geq 90$ & 3 & 1.9 & \\
\hline \multicolumn{4}{|c|}{ Study duration in a week } \\
\hline $0-1$ hour & 44 & 28.3 & \multirow{4}{*}{0.011} \\
\hline $1-3$ hours & 32 & 20.6 & \\
\hline $3-5$ hours & 29 & 18.7 & \\
\hline$>5$ hours & 50 & 32.2 & \\
\hline
\end{tabular}

$p<0.05$ is statistically significant 
and 'I can easily reach the resources related to this course' ( $1.45 \pm 0.8$ and $1.21 \pm 0.9$, respectively). The lowest score was ascribed to 'There is an association between the given anatomy education and clinical practice' $(0.21 \pm 0.2)$. The results were statistically significant $(p<0.05)$, but not statistically significantly different in the two genders $(p>0.05)$.

The relationship between the participants' scores for the duplicated control question was calculated by Pearson's product-moment correlation coefficient as $r=0.92, p<0.01$. Thus, it can be said that the students answered the questionnaire honestly.

It was determined that $48(30.96 \%)$ students completely liked to study the theoretical lessons, 23 (14.83\%) completely did not like, 61 (39.35\%) completely liked to study the practical lessons, and 5 (3.22\%) did not like (Table 2). These results reveal that students more liked to study practical lessons $(1.00 \pm 0.6)$.

Students listed their study materials as 5 basic educational resources for the theoretical part of the anatomy and 5 for the practical part, from the least used to the most. They made this ranking by giving numerical values between 1 and 5 for the educational materials they used while studying the theoretical part of the anatomy, and between 1 and 5 for the practical part. Thus, a mean and standard deviation value was obtained for each study material. According to this order, the course notes given by the lecturer are the first among the re-

Table 2. The questionnaire Likert scale items and the students' responses

\begin{tabular}{|c|c|c|c|c|c|c|c|}
\hline Statement & 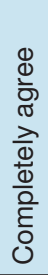 &  & 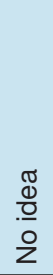 & 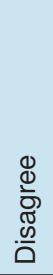 & 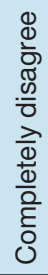 & Mean $\pm S D$ & $p$ \\
\hline I enjoy studying anatomy & 94 & 19 & 12 & 15 & 15 & $1.01 \pm 0.4$ & 0.001 \\
\hline I am interested in anatomy courses & 88 & 22 & 16 & 19 & 10 & $1.02 \pm 0.5$ & 0.004 \\
\hline Contents that I learned in this course aroused my curiosity & 74 & 52 & 20 & 4 & 5 & $1.17 \pm 0.4$ & 0.112 \\
\hline I can easily reach the resources related to this course & 71 & 55 & 21 & 7 & 1 & $1.21 \pm 0.9$ & 0.003 \\
\hline I have difficulty in learning the course & 61 & 46 & 13 & 23 & 12 & $0.78 \pm 0.4$ & 0.001 \\
\hline Anatomy courses motivate me for my carrier & 96 & 39 & 11 & 7 & 2 & $1.41 \pm 0.9$ & 0.001 \\
\hline I like studying the theoretical part of anatomy courses & 48 & 49 & 18 & 17 & 23 & $0.52 \pm 0.6$ & 0.004 \\
\hline I like studying the practical part of anatomy courses & 61 & 56 & 21 & 12 & 5 & $1.00 \pm 0.6$ & 0.001 \\
\hline The theoretical part of anatomy is given at a sufficient level & 76 & 21 & 14 & 17 & 27 & $0.65 \pm 0.8$ & 0.001 \\
\hline The practical part of anatomy is given at a sufficient level & 65 & 52 & 15 & 15 & 8 & $0.97 \pm 0.4$ & 0.001 \\
\hline The teaching method of the instructor affects my performance on this course & 56 & 19 & 36 & 15 & 29 & $0.37 \pm 0.1$ & 0.179 \\
\hline Lack of cadavers in anatomy education constitutes a deficiency in my education & 59 & 13 & 48 & 21 & 14 & $0.52 \pm 0.9$ & 0.243 \\
\hline I find sufficient the number of models in the laboratory & 36 & 90 & 10 & 10 & 9 & $0.21 \pm 0.8$ & 0.003 \\
\hline I find sufficient the time which is given to the theoretical part of anatomy courses & 78 & 33 & 14 & 16 & 14 & $0.93 \pm 0.5$ & 0.002 \\
\hline I find sufficient the time which is given to the practical part of anatomy courses & 69 & 32 & 19 & 30 & 25 & $0.58 \pm 0.6$ & 0.001 \\
\hline I think visuals are very important in anatomy courses & 70 & 32 & 24 & 23 & 6 & $0.88 \pm 0.3$ & 0.001 \\
\hline Anatomy is an important subject in physical therapy & 60 & 44 & 13 & 24 & 14 & $0.72 \pm 0.2$ & 0.001 \\
\hline It is difficult to understand and retain & 82 & 30 & 15 & 19 & 9 & $1.01 \pm 0.2$ & 0.002 \\
\hline Anatomy should only be studied as clinical anatomy & 72 & 41 & 13 & 14 & 15 & $0.90 \pm 0.9$ & 0.001 \\
\hline Anatomy is memorized by multiple readings & 58 & 17 & 37 & 14 & 29 & $0.30 \pm 0.1$ & 0.103 \\
\hline Anatomy courses motivate me for my carrier* & 98 & 39 & 9 & 8 & 1 & $1.45 \pm 0.8$ & 0.001 \\
\hline Anatomy education is very rigid & 86 & 24 & 5 & 21 & 19 & $0.88 \pm 0.3$ & 0.001 \\
\hline It is better to learn more practical issues than theoretical ones & 29 & 32 & 39 & 25 & 30 & $0.33 \pm 0.2$ & 0.070 \\
\hline Topics should change to be more congruent with physiotherapy practice & 36 & 32 & 22 & 21 & 44 & $0.25 \pm 0.1$ & 0.137 \\
\hline There is an association between the given anatomy education and clinical practice & 22 & 64 & 26 & 12 & 31 & $0.21 \pm 0.2$ & 0.015 \\
\hline There is little association between anatomy education and my future carrier & 40 & 24 & 45 & 21 & 25 & $0.21 \pm 0.9$ & 0.164 \\
\hline Classes are sometimes too long & 72 & 65 & 8 & 8 & 2 & $1.21 \pm 0.2$ & 0.001 \\
\hline
\end{tabular}

$p<0.05$ is statistically significant; data presented as frequency

duplicated question 
Table 3. Descriptive statistics of the study materials for theoretical and practical anatomy lectures

\begin{tabular}{|c|c|c|c|c|}
\hline Instruction & Materials & Mean $\pm S D$ & Median & $\begin{array}{c}p \\
K W\end{array}$ \\
\hline \multirow{5}{*}{$\begin{array}{l}\text { Please sort the materials that you use } \\
\text { in the practical lessons from the most } \\
\text { beneficial to the least }\end{array}$} & Course notes given by the lecturer & $2.37 \pm 0.91$ & 3 & \multirow{5}{*}{0.042} \\
\hline & Textbook recommended by the lecturer & $1.74 \pm 0.82$ & 2 & \\
\hline & Anatomical atlas (book) & $2.58 \pm 1.21$ & 2 & \\
\hline & Anatomical atlas (interactive software) & $3.17 \pm 1.06$ & 3 & \\
\hline & Video records & $3.58 \pm 1.12$ & 4 & \\
\hline \multirow{5}{*}{$\begin{array}{l}\text { Please sort the materials that you use } \\
\text { in the theoretical lessons from the most } \\
\text { beneficial to the least }\end{array}$} & Course notes given by the lecturer & $3.88 \pm 1.17$ & 3 & \multirow{5}{*}{0.015} \\
\hline & Textbook recommended by the lecturer & $1.17 \pm 0.83$ & 2 & \\
\hline & Anatomical atlas (book) & $2.91 \pm 1.20$ & 2 & \\
\hline & Anatomical atlas (interactive software) & $2.88 \pm 0.93$ & 2 & \\
\hline & Voice records of the lecturer & $3.12 \pm 0.30$ & 3 & \\
\hline
\end{tabular}

KW - Kruskal-Wallis H test

$p<0.05$ is statistically significant

Table 4. Systems that students learned the best and worst and found the most interesting

\begin{tabular}{|l|c|c|c|c|}
\hline Systems & System found the most interesting & System learnt best & System learnt worst & $p$ \\
\hline Musculoskeletal system & $27(17.41)$ & $107(69.03)$ & $21(13.54)$ & 0.002 \\
\hline Circulatory system & $9(5.80)$ & $34(21.93)$ & $112(72.25)$ & 0.001 \\
\hline Respiratory system & $39(25.16)$ & $23(14.83)$ & $93(60)$ & 0.002 \\
\hline Urinary system & $58(37.41)$ & $52(33.54)$ & $45(29.03)$ & 0.147 \\
\hline Genital system & $63(40.64)$ & $58(37.41)$ & $34(21.93)$ & 0.041 \\
\hline Endocrine system & $117(75.48)$ & $21(13.54)$ & $27(17.41)$ & 0.001 \\
\hline Digestive system & $34(21.93)$ & $41(26.45)$ & $80(51.61)$ & 0.003 \\
\hline Nervous system & $102(65.80)$ & $48(30.96)$ & $5(3.22)$ & 0.002 \\
\hline
\end{tabular}

$p<0.05$ is statistically significant; data presented as frequency and percentage

sources used by the participants while studying the theoretical part of anatomy, followed by the voice records of the lecturer, anatomical atlas, interactive atlas, and the textbook recommended by the lecturer (Table 3).

For the practical part of the anatomy, the students ordered the materials (from the most beneficial to the least) as follows: course records (video), interactive atlas, atlas (printed book), course notes (slides), and textbook (Table 3). There were no gender differences between the rankings $(p>0.05)$. The participants pointed at video records as the most beneficial study material for the practical part of anatomy (3.58 \pm 1.12$)$, and course notes given by the lecturer for the theoretical part $(3.88 \pm 1.17)(p<0.05)$. The textbook recommended by the lecturer was found as the least beneficial study material for both practical $(1.74 \pm 0.82)$ and theoretical part of anatomy $(1.17 \pm 0.83)$.

Overall, $75.48 \%$ of the students stated that the most interesting system was the endocrine system. The musculoskeletal system was learnt the best by $69.03 \%$ of students. For $72.25 \%$ of the participants, the system that they learned the worst was the circulatory system (Table 4).

\section{Discussion}

Student feedback is one of the most common, reliable and valid methods for assessing the educational effectiveness
$[11,12]$. Regular evaluation of students' opinions about the anatomy education will contribute greatly to improving the quality of education, eliminating deficiencies, and developing new strategies. Therefore, student feedback is important for achieving the goals in anatomy education [13]. This study addressed the perception of anatomy education among students during the academic year 2018/2019. It was essentially a curriculum evaluation study designed to determine the students' attitudes to their anatomy teaching.

There are several studies evaluating medicine faculty students' views about anatomy education [14, 15]. However, studies investigating the opinions of physiotherapy students about anatomy education are rare $[8,16,17]$. Physiotherapy students' views should be examined, and necessary updates in education methods and curriculum should be done. Revisions may enhance the students' motivation and, consequently, bring improvements in such fields as academic learning and class attendance.

Several previous studies have shown that class attendance is an important predictor of grade point average [18]. In a study, however, no statistically significant relationship between class attendance and students' grade point average was identified [19]. Although there are different results in the literature, no correlation was found between the grade point average and course attendance among the participants of the present study. 
As stated in many studies, gender differences in the learning style, academic ability, and grade point average are generally expected [20]. In line with the literature emphasizing gender differences, the grade point average of female students was significantly higher than that in males in this study. Also, a moderate level correlation was found between the study time in a week and grade point average in female students, but no such correlation was observed in males.

Regardless of whether male or female, today's students are comfortable with technology and influenced by its use [13]. Traditional learning methods and environments are thought to be inadequate to respond to the divergent expectations of generation Z (born in 1995 or later), born and grown in the digital age. For this reason, it has become imperative for educational institutions to support their curricula with innovations and advanced technology [21, 22]. In the present survey, students listed their study materials, and the textbook recommended by the lecturer was found the least beneficial material for studying both practical and theoretical part of anatomy. It can be assumed that this result is due to the fact that generation $\mathbf{Z}$ is pleased to use technology rather than traditional education materials such as books. Moreover, the participants expressed complaints such as 'Classes are sometimes too long,' 'Anatomy education is very rigid,' 'It is difficult to understand and retain,' 'I have difficulty in learning the course' (Table 2). It can be thought that these complaints stem from the fact that generation $Z$ grew up in a very complex media and computing environment, had a very good grasp and internalization of the Internet. So, traditional anatomy education methods seem very far from their expectations.

The curricula of all health professional courses have an important foundation of human anatomy. Especially, physical therapists are considered referral-based, musculoskeletalfocused practitioners with a more specialized knowledge of anatomy [23]. It is also known that the physiotherapy and rehabilitation curriculum focuses on musculoskeletal anatomy [24]. Therefore, the musculoskeletal system is the subject that physiotherapy students learn best and in fact they have to learn best. In the present research, the students stated that the system which they learned the best was the musculoskeletal system (Table 4). From the results provided in Table 4, it can be concluded that revisions should be made in the anatomy curriculum of physiotherapy.

Education with cadavers and dissection is a very conventional method for teaching anatomy [25]. There are many studies showing that medical education cannot be effective without cadavers [26]. Nevertheless, some researchers believe that a well-designed anatomical curriculum without cadavers might be as good as or even better than education with cadavers for learning gross anatomy [27]. In physiotherapy curricula of many universities, also in Hasan Kalyoncu University, anatomy education is carried out without cadavers. Additionally, in this study, the responses to the statement 'Lack of cadavers in anatomy education constitutes a deficiency in my education' were not found statistically significant (Table 2).

To sum up, students' views about traditional anatomy education were examined in this study. The findings of the research may provide different perspectives to the specialists of anatomy education.

\section{Limitations}

The study is limited with the answers of students who participated in the survey. The collected information is as- assumed to give their answers honestly. The gender ratio may not be reflective of the whole student population. Also, the sample size of this local evaluation study could be enlarged in subsequent studies on the physiotherapy curriculum. This was a cross-sectional study by design but perhaps could be strengthened by a longitudinal approach, and the questionnaire could be validated in future studies.

\section{Conclusions}

As a result of this study, it is anticipated that interactive educators would be more helpful to teach the lessons. Moreover, it seems that anatomy education in physiotherapy and rehabilitation departments may need revisions to enhance students' motivation and, consequently, improve academic learning.

\section{Disclosure statement}

The author does not have any financial interest and did not receive any financial benefit from this research.

\section{Conflict of interest}

The author states no conflict of interest.

\section{References}

1. Arifoglu Y. Anatomy: all aspects [in Turkish]. Istanbul: Istanbul Tip Kitabevi; 2017.

2. Ocak MA, Topal AD. Blended learning in anatomy education: a study investigating medical students' perceptions. Eurasia J Math Sci Technol Educ. 2015;11(3):647-683; doi: 10.12973/eurasia.2015.1326a.

3. Singh R, Shane Tubbs R, Gupta K, Singh M, Jones DG, Kumar R. Is the decline of human anatomy hazardous to medical education/profession? A review. Surg Radiol Anat. 2015;37(10):1257-1265; doi: 10.1007/s00276015-1507-7.

4. McLachlan JC, Patten D. Anatomy teaching: ghosts of the past, present and future. Med Educ. 2006;40(3):243-253; doi: 10.1111/j.1365-2929.2006.02401.x.

5. Shead D, Roos R, Olivier B, Ihunwo AO. Opinions of South African physiotherapists on gross anatomy education for physiotherapy students. S Afr J Physiother. 2019;75(1): 1318; doi: 10.4102/sajp.v75i1.1318.

6. Arasil T, Kayhan O. The status of rehabilitation in Turkey. Disabil Rehabil. 1997;19(9):379-381; doi: 10.3109/0963 8289709166557.

7. Gürses HN, Alemdaroğlu I, Tanriverdi M. Investigation and curriculum analysis of the physiotherapy and rehabilitation faculty department/schools in Turkey. Turk J Physiother Rehabil. 2014;25(1):16-27.

8. Shead DA, Roos R, Olivier B, Ihunwo AO. Gross anatomy education for South African undergraduate physiotherapy students. Anat Sci Educ. 2018;11(6):554-564; doi: 10.1002/ase.1763.

9. Turney BW. Anatomy in a modern medical curriculum. Ann R Coll Surg Engl. 2007;89(2):104-107; doi: 10.1308/ 003588407 X168244.

10. Regan de Bere S, Mattick K. From anatomical 'competence' to complex capability. The views and experiences of UK tutors on how we should teach anatomy to medical students. Adv Health Sci Educ Theory Pract. 2010; 15(4):573-585; doi: 10.1007/s10459-010-9220-0.

11. Skovholt K. Anatomy of a teacher-student feedback encounter. Teach Teach Educ. 2018;69:142-153; doi: 10.1016/j.tate.2017.09.012. 
12. Penny AR. Changing the agenda for research into students' views about university teaching: four shortcomings of SRT research. Teach High Educ. 2003;8(3):399-411; doi: 10.1080/13562510309396.

13. Dent J. Evaluating your own performance in a lecture. In: Chan LK, Pawlina W (eds.), Teaching anatomy: a practical guide, $1^{\text {st }}$ ed. New York: Springer; 2015; 81-87.

14. Cetkin M, Turhan B, Bahşi I, Kervancioglu P. The opinions of medicine faculty students about anatomy education. Gaziantep Med J. 2016;22(2):82-88; doi: 10.5578/ GMJ.32156.

15. Doğan Z, Uludağ Ö, Ateşoğlu S, Üçkardeş F, Aydin A. Opinions of Adıyaman University Dental Faculty students on interactive anatomy education. SDU J Health Sci Inst. 2018;9(2):48-53; doi: 10.22312/sdusbed.440751.

16. Youdas JW, Krause DA, Hellyer NJ, Rindflesch AB, Hollman $\mathrm{JH}$. Use of individual feedback during human gross anatomy course for enhancing professional behaviors in doctor of physical therapy students. Anat Sci Educ. 2013;6(5):324-331; doi: 10.1002/ase.1356.

17. Fabrizio PA. Oral anatomy laboratory examinations in a physical therapy program. Anat Sci Educ. 2013;6(4): 271-276; doi: 10.1002/ase.1339.

18. Lukkarinen A, Koivukangas $P$, Seppälä T. Relationship between class attendance and student performance. Procedia Soc Behav Sci. 2016;228:341-347; doi: 10.1016/ j.sbspro.2016.07.051.

19. Eisen DB, Schupp CW, Isseroff RR, Ibrahimi OA, Ledo L, Armstrong AW. Does class attendance matter? Results from a second-year medical school dermatology cohort study. Int J Dermatol. 2015;54(7):807-816; doi: 10.1111/ ijd.12816.

20. Anderton RS, Evans T, Chivers PT. Predicting academic success of health science students for first year anatomy and physiology. Int J High Educ. 2016;5(1):250-260; doi: 10.5430/ijhe.v5n1p250.

21. Kızıl H, Şendir M. Innovative approaches in nursing education. J Hum Sci. 2019;16(1):118-125; doi: 10.14687/ jhs.v16i1.5437.

22. Bahşi I, Çetkin M, Kervancıoğlu P, Orhan M, Ayan H, Sayin S. Evaluation of the efficiency, way of teaching, and attendance control of medical faculty courses [in Turkish]. Genel Tip Derg. 2018;28(3):89-95; doi: 10.15321/ GenelTipDer.2018343480.

23. Valenza MC, Castro-Martín E, Valenza G, Guirao-Piñeiro M, De-la-Llave-Rincón Al, Fernández-de-las-Peñas C. Comparison of third-year medical and physical therapy students' knowledge of anatomy using the carpal bone test. J Manipulative Physiol Ther. 2012;35(2):121126; doi: 10.1016/j.jmpt.2011.12.005.

24. Sytsma TT, Haller EP, Youdas JW, Krause DA, Hellyer NJ, Pawlina W, et al. Long-term effect of a short interprofessional education interaction between medical and physical therapy students. Anat Sci Educ. 2015;8(4):317-323; doi: 10.1002/ase.1546.

25. Kerby J, Shukur ZN, Shalhoub J. The relationships between learning outcomes and methods of teaching anatomy as perceived by medical students. Clin Anat. 2011;24(4):489-497; doi: 10.1002/ca.21059.

26. Anyanwu GE, Ugochukwu Al. Impact of the use of cadaver on student's ability to pass anatomy examination. Anatomy. 2010;4(1):28-34; doi: 10.2399/ana.09.022.

27. Wilson AB, Miller CH, Klein BA, Taylor MA, Goodwin M, Boyle EK, et al. A meta-analysis of anatomy laboratory pedagogies. Clin Anat. 2018;31(1):122-133; doi: 10.1002/ ca.22934 